\title{
CULTO Y DEVOCIÓN AL SAGRADO CORAZÓN DE JESÚS UNA APROXIMACIÓN HISTÓRICA
}

\author{
Diác. Santiago Alemán
}

Esta es la reelaboración de un texto que fue escrito originalmente para la materia de "Historia de la Iglesia III", del $3^{\circ}$ año de Teología del Seminario Mayor San José de La Plata. La intención consiste en describir el surgimiento histórico de la devoción al Sagrado Corazón de Jesús, bajo la forma particular en la que se ha difundido en toda la cristiandad a lo largo de los últimos tres siglos, constituida ya en patrimonio común de la liturgia y la piedad de la Iglesia occidental. Repasando los hitos fundamentales en este desarrollo, podremos comprender y profundizar los aspectos esenciales de un modo de adoración a Nuestro Señor Jesucristo en la imagen de su Sagrado Corazón.

\section{Presentación del tema}

En la encíclica Haurietis Aquas, de s.s. Pío XII, sobre el culto y la devoción al Sagrado Corazón de Jesús, se afirma que este modo de referirse a la segunda Persona de la
Santísima Trinidad no está ausente en la Divina Revelación, tanto escrita como oral, ni en la doctrina de los Padres y teólogos de la Iglesia a través de los siglos, (Pío XII, 1956, $\left.n^{\circ} 5, n^{\circ} 25\right)$ sino que, más bien, halla en ellas su origen y fundamento. Este tema está bien desarrollado en los $n^{\circ}$ 7 a 14 de la mencionada encíclica.

Sin embargo, el mismo documento reconoce, al ocuparse de la historia del culto al Sagrado Corazón, que su "manifestación clara y su admirable difusión en toda la Iglesia se ha realizado en tiempos no muy remotos de nosotros, sobre todo después que el Señor mismo reveló este divino misterio a algunos hijos suyos, y los eligió para mensajeros y heraldos suyos, luego de haberles colmado con abundancia de dones sobrenaturales". (Pío XII, $\left.n^{\circ} 25\right)$. $Y$, más adelante, enumera sucintamente las figuras más notables en el desarrollo de esta expresión de la piedad cristiana, remontándose, entre los más antiguos, a san Alberto Magno, 


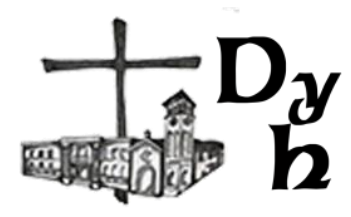

pasando por santa Catalina de Siena y san Francisco de Sales, y haciendo una especial mención de san Juan Eudes, quien compuso el primer oficio litúrgico en honor del Sagrado Corazón. (Pío XII, n²6).

Por otra parte, reconoce un lugar central a santa Margarita María de Alacoque, mencionada de hecho en el subtítulo correspondiente; según el documento, la santa "merece un puesto especial porque su celo, iluminado y ayudado por el de su director espiritual -el beato Claudio de la Colombière-, consiguió que este culto, ya tan difundido, haya alcanzado el desarrollo que hoy suscita la admiración de los fieles cristianos, y que, por sus características de amor y reparación, se distingue de todas las demás formas de la piedad cristiana." (Pío XII, $\left.n^{\circ} 26\right)$.

La Historia de la Iglesia Católica de Llorca, Villoslada y Montalbán, describe este acontecimiento de la siguiente manera:

Esta devoción, que hecha sus brotes en los místicos medioevales, particularmente en Santa Gertrudis, adquiere sus modalidades típicas de consagración y reparación en el siglo XVII gracias a humilde religiosa de la Visitación de Nuestra Señora, o salesa, Santa Margarita María de Alacoque (1647-1690). Por el mismo tiempo, Juan Eudes propagaba ardientemente la devoción a los Sagrados Corazones de Jesús y María; pero el instrumento elegido por Dios fue la Santa, que por indicación y expresa voluntad del mismo Corazón de Jesús tuvo por colaboradores al infatigable Padre La Colombière y a los Padres de la Compañía de Jesús. Las revelaciones principales se manifestaron a la Santa en los años 1673-1675 (Llorca, Villoslada, \& Montalbán, 1960, pp. 349-350).

Este suceso particular, cuyas coordenadas históricas podemos ubicar genéricamente en la Francia del siglo XVII, se fue constituyendo, con el correr de los años, en una nota distintiva de la historia de la Iglesia en la modernidad. Por ello, queremos abocarnos a él en estas páginas.

\section{Contexto histórico}

Debemos situarnos, como se ha dicho, en el siglo XVII francés. Europa lleva ya largas décadas de guerras de religión y de consiguiente confusión doctrinal y cansancio moral. Francia cerró el siglo precedente signada por las encarnizadas guerras entre católicos y hugonotes (cf. Llorca, Villoslada, \& Montalbán, 1958, pp. 902-912). La necesidad sentida por la nobleza y por el mismo pueblo de dar fin a los enfrentamientos, así como el temor de quedar bajo la égida de España y de Felipe II, llevó a una progresiva aceptación práctica y legal del protestantismo (apoyado militarmente desde Alemania) y a un resurgimiento de la tendencia conciliarista y excesivamente localista, bajo la 
forma del galicanismo (cf. Llorca, Villoslada, \& Montalbán, 1960, pp. 69-83). Así, bajo los reinados de Enrique IV de Navarra (convertido del protestantismo para recibir la corona) y sobre todo de Luis XIII y Luis XIV, la iglesia francesa, cada vez más, se fue subordinando a los intereses y necesidades de la corona.

Con este marco, la reforma promovida por el Concilio Tridentino tuvo en tierra francesa una cierta dilación. Sin embargo, ante la crisis religiosa, que se concretaba tanto en una pérdida del fervor y de la vida sacramental en los fieles como en una escandalosa relajación intelectual y moral en el clero, no tardaron en surgir figuras de gran lucidez y virtud, que dieron al naciente 1600 un impulso de conversión y renovación, cuyos frutos se extendieron a los siglos venideros.

Se narra en la "Vida Popular" de san Juan Eudes (1601-1680):

¿Que ignorancia y qué libertinaje los de aquella época! Dos azotes, la herejía de Calvino y la guerra civil se hacían sentir. El clero mismo dejaba sin instrucción y a menudo sin sacramentos; el pueblo, principalmente en los campos, ignoraba las verdades más elementales del Evangelio, y se dejaba arrastrar por la corrupción, al perjurio y al homicidio. Necesitábanse remedios adecuados: instruir a los pueblos, alejarlos del vicio y restablecer en ellos la frecuentación piadosa de los sacramentos. Esta obra la

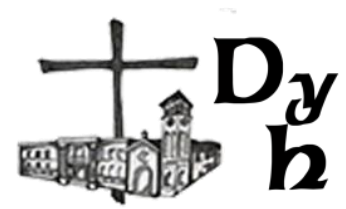

emprendieron, a principios del siglo XVII, santos sacerdotes y fervorosos religiosos, entre otros, San Vicente de Paúl, el señor Olier, los Padres Nobletz y Maunior y algunos oratorianos (El Beato Juan Eudes, Vida Popular, 1922, pp. 16-17).

No figura aquí, porque es abundantemente nombrado en toda esta biografía, el Cardenal de Bérulle (1575-1629), fundador del oratorio francés y padre espiritual de Juan Eudes. Indudablemente, a esta lista hay que sumar, como figuras fundamentales para la vida espiritual francesa, a San Francisco de Sales (1567-1622) y, con él, a Santa Juana Francisca de Chantal, fundadores de las Hermanas de la Visitación. Afirma el P. Rotureau, sacerdote del Oratorio fundado por de Bérulle, que son tres los nombres que representan el renacimiento religioso francés durante la primera mitad del siglo XVII: San Francisco de Sales, célebre predicador y director espiritual; San Vicente de Paúl, apóstol de la caridad para con los enfermos y desvalidos; el Cardenal Pedro de Bérulle, fundador de la Escuela de espiritualidad francesa (cf. del Carmen Blassi, 2001, p. 7).

Sobre esta misma materia, y en el mismo sentido, se expresa A. Dodin en un artículo sobre la espiritualidad francesa del siglo XVII:

En este territorio y en esta época corre el siglo de oro de la espiritualidad francesa (...) Aquí y allí está caracterizada por la floración simultánea de varias escuelas de vida religiosa. Pero 
en Francia hay que colocar al lado de la prosperidad del Carmelo, de la Compañía de Jesús, de la Orden Franciscana, el nacimiento rápido y el desarrollo fertilizante de dos movimientos: el Salesianismo y el Berulismo. Sin duda alguna la escuela beruliana ha contribuido, más que ninguna otra, a dar a los espirituales de entonces un movimiento, un estilo propio, incluso un ambiente religioso particular" (Dodin, 1969, p. 437).

Otro elemento característico ineludible de la Iglesia francesa de esos años, pero esta vez por sus nefastos efectos, lo constituye la herejía jansenista. Jansenio (15851638), de origen Holandés y profesor en Lovaina, fue heredero intelectual y ferviente propagador de las doctrinas de Miguel Bayo (15131589). El núcleo fundamental de esta corriente se presenta como un eco de las dudas que había sembrado en los espíritus teológicos la encarnizada querella de auxiliis (sobre la relación entre la Gracia divina y la libertad humana) y, a su vez, como una presunta síntesis entre las doctrinas católica y protestante de la justificación. Según el distorsionado augustinismo de Jansenio, la debida primacía de la Gracia propuesta por el gran doctor de occidente en su oposición a la herejía pelagiana debe extremarse hasta la afirmación de que todo acto de quien no está en gracia es formalmente pecaminoso, porque el hombre luego de la caída se halla totalmente sumido en la concupiscencia. La gracia, por otro lado, actúa de modo 'determinístico' en el hombre pero sin él; pues, en tanto es eficaz, la libertad humana de ningún modo puede rechazarla. La liberación gratuita de la concupiscencia se le impone al hombre como desde fuera. Así, hay que decir que solo reciben la gracia aquellos que ya no pecan y que finalmente se salvan $y$, por ende, la obra de Jesucristo y la salvación están reductivamente ordenadas a los predestinados (cf. Delgado, 2016, pp. 36-43).

La mayor influencia de esta herejía se hizo sentir en Francia durante el siglo XVII, por la activa mediación de Duvergier, abad de Sait-Cyran, y su influencia en el monasterio de Port Royal (cf. Llorca, Villoslada, \& Montalbán, 1960, pp. 184-261). Las consecuencias morales y espirituales de esta doctrina fueron un exacerbado rigorismo y ascetismo (que sería el principal signo de predestinación), una piedad abstracta, que acentuaba la infinita distancia entre Dios y la criatura y, por último, un temeroso distanciamiento de los sacramentos $y$, en particular, de la Eucaristía. Entre los principales enemigos del jansenismo estuvieron los padres de la Compañía de Jesús $y$, como se verá más adelante, también todos aquellos que promovieron la devoción y culto del Sagrado Corazón. 


\section{Antecedentes remotos}

Para

adentrarnos

ordenadamente en el tema que nos interesa, podemos seguir el itinerario que nos propone el artículo del Diccionario de Espiritualidad, dirigido por el P. Marcel Viller S.I., dedicado justamente al tema del Sagrado Corazón ${ }^{1}$. Allí (como en la apresurada enumeración que hacía la Encíclica Haurietis) las raíces históricas de nuestra devoción se remontan hasta los doctores y místicos de la escolástica cristiana. Mientras el documento pontificio señalaba entre los más primitivos devotos del Corazón de Cristo a san Alberto Magno y san Buenaventura (Pío XII,

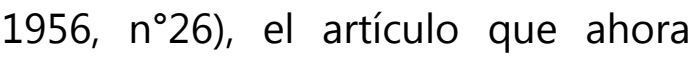
seguimos retrocede hasta el siglo XII, a las venerables figuras de san Anselmo primero $y$, luego, de san Bernardo (cf. Viller, 1948, p. 1026). Todos estos casos, sumados a los de Guillermo de san Thierry, Gilberto de Holanda, Hugo y Ricardo de san Víctor, ponen de manifiesto que los albores de esta devoción surgen de la piadosa contemplación de Cristo crucificado, de sus Santas Llagas y particularmente de su costado abierto (p. 1027). Expresa este proceso la Enciclopedia Cattolica: "A través del costado rasgado se llega al corazón y comienza a establecerse una fusión entre el corazón y el amor de Jesús" (Pontificio Ateneo Lateranense, 1950, p. 1059). El P. Huerga, O.P., nos da el marco

${ }^{1}$ Cf. Marcel Viller, S.I. (ed.); Diccionaire de Spiritualité (París 1948); Fascicule XI; art: Coeur (Sacré), II Histoire de la dévotion. general de esta corriente (que engloba piedad popular y vida contemplativa) bajo el título de "devociones pasionarias". La veneración de la Santa Cruz y sus reliquias, el rezo del Vía Crucis o la plegaria del Anima Christi, son elementos que tipifican este movimiento que atraviesa toda la Europa occidental desde la era de las Cruzadas hasta entrado el siglo XV (Huerga, 1969, pp. 62-64).

Son muy significativas las manifestaciones místicas a las santas Lutgarda (1182-1246), Gertrudis (1243-1300?) y Matilde (+1298). Entre los franciscanos se encuentran quienes reciben y profundizan esta corriente de piedad. En primer lugar el mismo Francisco de Asís, unido místicamente al Señor crucificado, y luego san Buenaventura, san Antonio de Padua, santa Margarita Cortona (1247-1297), santa Ángela de Foligno (1246-1309), san Bernardino de Siena (1380-1444), predicador del Nombre de Jesús (cf. Viller, 1948, pp. 10271028).

Entre los siglos XIV y XVI fue cristalizándose la devoción del Sagrado Corazón, especialmente en la Germania del sur, entre los místicos renanos, los cartujanos de Colonia, y el influjo de la llamada devotio moderna, que tuvo su centro principal en los Países Bajos (pp. 1028-1030). Se destaca Lanspergio el cartujo (1489-1539), que en su monasterio promovió directamente la honra del Corazón físico del Señor.

"De Alemania y los Países Bajos, entró la devoción en Francia" 


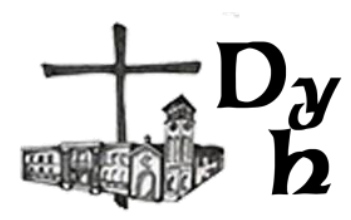

(p. 1030). Y ya para comienzos del siglo XVII, aunque todavía en los ambientes monásticos, el Sagrado Corazón encuentra terreno fértil en tierras francesas. Sobresalen los monasterios de Mont-Martre, Val de Grâce y particularmente el de las Benedictinas de Nuestra Señora del Calvario, fundadas por el Padre Joseph (1577-1638) en París, que tributaron culto público al Corazón de Jesús.

\section{Preparación inmediata}

Ubicados ya en el mismo siglo $y$ el mismo suelo en el que encontraremos aquel acontecimiento crucial para el surgimiento de la devoción al Sagrado Corazón como hoy la conocemos, debemos detenernos en los elementos directamente preparatorios o dispositivos de este suceso: la teología y espiritualidad de San Francisco de Sales, con todos sus frutos apostólicos; y la figura y obra de San Juan Eudes, apóstol de los Corazones de Jesús y María. Ambos santos, así como sus respectivas misiones y fundaciones, prepararon maravillosamente el terreno de la Iglesia para que pudiesen germinar y dar grandiosos frutos las revelaciones del Sagrado Corazón a santa Margarita María. El primero lo hizo más claramente en el plano espiritual y literario; el segundo, con fervoroso despliegue en lo misional y ejecutivo. Los dos se anticiparon de modo providencial al culto del Corazón de Jesús como la cristiandad lo conocería pocas décadas después.
San Francisco de Sales, sumamente devoto del Sagrado Corazón de Jesús, transmitió este sentimiento suyo en las Visitandinas y confió su Congregación al Sagrado Corazón de Jesús (...) Aún con tal difusión, la devoción permanecía puramente privada. San Juan Eudes fue el iniciador y apóstol del culto litúrgico de los Sagrados Corazones de Jesús y María (Pontificio Ateneo Lateranense, 1950, p. 1060).

En las cartas y escritos de San Francisco de Sales $y$, de un modo singular en su Tratado del Amor de Dios, se nos hace patente la centralidad en la que puso al amor divino manifestado en Jesucristo y particularmente significado en su Sagrado Corazón. Dirigiéndose a Santa Francisca de Chantal decía “¡Cuán bueno es este Señor mi querida hija! ¡Cuán afable es su corazón! Quedémonos en Él, en este santo domicilio; viva siempre ese corazón en los nuestros, hierva siempre esa sangre en las venas de nuestra alma" (Francisco de Sales, 1945b, p. 152). Y en otra oportunidad: "El Salvador al morir nos dio vida por la herida de su Sagrado Corazón..." (Francisco de Sales, 1945a, p. 167). Sin ahondar en la multitud de pasajes elocuentes que podríamos encontrar en el gran Tratado que el santo dedicó al Amor de Dios, nos basta citar de las páginas finales:

Estos beneficios no nos inflamarán de amor, si no miramos la voluntad eterna que nos los prepara, y el Corazón del Jesús que nos los mereció con 
tantas penas, sobre todo con su muerte y Pasión (...) El Calvario es, Teótimo, el monte de los amantes. Amor que no toma su origen en la pasión de Jesús es frívolo y peligroso. Desgraciada es la muerte sin el amor de Jesús. Amor y muerte se hallan de tal manera unidos en la pasión de Jesús, que no pueden estar en el corazón uno sin otro (Francisco de Sales, 2006, pp. 739-740).

Es difícil pensar que esto no dispuso favorablemente a la hija de la Visitación, Margarita de Alacoque, a recibir con fe y amor las manifestaciones del Corazón de Cristo.

En cuanto a la misión de San Juan Eudes, habría que hablar, más que de un factor preparatorio, de una causa convergente y fundamental. Junto con las revelaciones de Paray-le-Monial, esta misión facilita la instauración definitiva de la devoción y culto del Sagrado Corazón de Jesús en Francia y en toda la Iglesia. El citado Diccionario de Espiritualidad considera que en la espiritualidad de este santo no hay una referencia directa al Corazón de carne del Señor, sino más bien a su amor, su alma y sus sentimientos, en unión con los de su Santísima Madre (cf. Viller, 1948, p. 1032). Además, como señala Pío XII, los rasgos típicos de amor y reparación los adquiere la devoción recién con Santa Margarita (Pío XII, 1956, n²6). Sin embargo -y ninguno de estos dos textos lo oculta-, la tarea de predicación, fundación y misión realizada por el apóstol de los Sagrados Corazones, unida a su tarea de confección del oficio litúrgico de los Corazones primero, y luego del Corazón de Jesús, es inestimable en función de la extensión de este culto. Tanto la Congregación de Jesús y María como, luego, la de Nuestra Señora de la Caridad del Buen Pastor, fundadas por el P. Eudes, fueron focos de desarrollo y promoción de la piedad pública hacia el Corazón de Cristo, antes y después de los mensajes recibidos por la salesa de Paray (cf. García Herreros, 1943).

Según nos narra la Vida popular del santo anteriormente citada, él, "después de dar con sus misioneros una fervorosísima misión en Rennes, logró que el señor obispo aprobara en aquella Diócesis la celebración de 'la fiesta del Corazón adorable de Nuestro Señor Jesucristo'. Esta fue la primera vez que en la Iglesia se autorizó esta fiesta oficialmente. Después, los obispos de Countances, de Evreux, de Bayeux, de Lisieux, de Ruan, autorizaron para sus Diócesis respectivas la misma fiesta entre los años 1670 y 1671" (García Herreros, 1943, p. 42). La fiesta se celebraría oficialmente en las casas eudistas de Francia para 1672, el día 20 de octubre.

Juan Eudes, como buen hijo y discípulo del Cardenal de Bérulle, realizó una encomiable tarea para la instauración y organización de seminarios en toda Francia, tanto religiosos como diocesanos, según el ideal propuesto por el Concilio de 


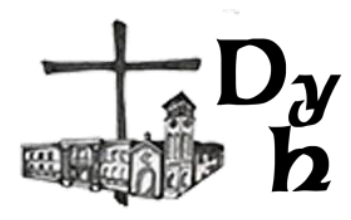

Trento. También esta debe ser considerada como una causa discreta pero poderosa de la propagación del amor por el Sagrado Corazón.

Todo esto nos deja a las puertas del momento que el Divino Redentor había prefijado para dar personal y definitivamente a conocer el anhelo de su Sagrado Corazón, en cuanto a la devoción por la que se lo honraría en adelante como signo especialísimo de su Amor salvífico.

\section{Acontecimiento}

El suceso que vimos mencionado por Pío XII, cuando decía que la devoción al Sagrado Corazón "adquiere sus modalidades típicas de consagración y reparación en el siglo XVII gracias a humilde religiosa de la Visitación de Nuestra Señora, o salesa, Santa Margarita María de Alacoque (1647-1690)", ocupa un lugar principal en el artículo que hemos estado siguiendo.

Hasta 1675 fue esta la devoción de algunas congregaciones religiosas, de almas privilegiadas diseminadas por Alemania, Países Bajos, Francia; hoy es la devoción de la Iglesia universal, nuestra fuerza, nuestra alegría, la fuente de nuestra confianza: la palabra de una joven religiosa obró esta maravilla. Santa Margarita María no encontró por sí misma esta devoción: le fue revelada por Nuestro Señor. Apoyada en el dogma, la devoción al Sagrado Corazón se mantiene por ella misma. Jesús nos ha querido decir cómo comprenderla y practicarla. En el mes de junio de 1675, posiblemente el 16, durante la octava del Santísimo Sacramento, Nuestro Señor se apareció a la Santa, y mostrándole su Corazón le dijo: 'He aquí el Corazón que tanto ha amado a los hombres, que nada ha perdonado hasta agotarse $y$ consumirse para demostrarles su amor; y en reconocimiento no revivo de la mayor parte más que ingratitudes, a causa de sus irreverencias y sacrilegios y las frialdades y menosprecios que tienen para conmigo en este sacramento de amor. Pero lo que me es más doloroso es que aquellos corazones que se me han consagrado obren así. Es por esto que te pido que el primer viernes tras la octava del Santísimo Sacramento sea dedicada una fiesta particular para honrar mi Corazón, comulgando ese día y haciendo en él una reparación de honor, mediante un digno desagravio, para reparar las injurias que ha recibido mientras ha estado expuesto en los altares' (Viller, 1948, pp. 1033-1034).

El acontecimiento aquí narrado, conocido como la Gran Revelación, constituyó ciertamente un antes y un después en el desarrollo de la devoción al Sagrado Corazón. En las mismas palabras del Señor que acabamos de recordar, recogidas en las memorias de la santa, se ve con claridad el paso, que se efectuará efectivamente más tarde, de la veneración privada al Corazón de Jesucristo al culto 
público y oficial; "sea dedicada una fiesta particular para honrar mi Corazón". Esta proyección que podríamos llamar eclesial y también misionera de las revelaciones privadas a las que nos referimos se ve ya expresada en las primeras manifestaciones del Señor a santa Margarita:

Me hizo reposar por muy largo tiempo sobre su pecho divino, en el cual me descubrió todas las maravillas de su amor y los secretos inexplicables de su Corazón Sagrado, que hasta entonces me había tenido siempre ocultos. (...) Él me dijo: 'Mi divino Corazón está tan apasionado de amor por los hombres, y por ti en particular, que no pudiendo ya contener en sí mismo las llamas de su caridad ardiente, le es preciso comunicarlas por tu medio, y manifestarse a todos para enriquecerlos con los preciosos tesoros, que te descubro, y los cuales contienen las gracias santificantes y saludables necesarias para separarles del abismo de perdición. Te he elegido como un abismo de indignidad y de ignorancia a fin de que sea todo obra mía' (Margarita María de Alacoque, 1890, pp. 106-107).

Como también subraya el citado Diccionario, el mismo Señor al encargarle tamaña tarea a la joven religiosa de Paray-le-Monial, le promete asistirla con la ayuda de su 'amigo y siervo fiel' P. Claudio de la Colombière (1641-1682). Leemos en la Autobiografía de la santa:

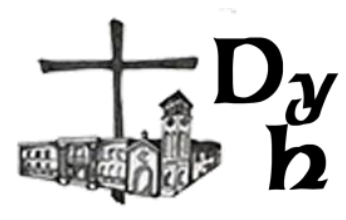

Me hicieron hablar con algunas personas doctas, las cuales, muy lejos de asegurarme en mi camino, aumentaron todavía más mis penas. Finalmente envió aquí Nuestro Señor al P. La Colombière, al cual había yo asegurado ya desde el principio, que mi soberano Maestro me prometió, poco después de habermeconsagrado a Él, que me enviaría un servidor suyo, a quien quería manifestase según la inteligencia que sobre ello me daría, todos los secretos de su Sagrado Corazón, que Él me había confiado; pues me le enviaba para asegurarme en mis caminos, y para repartir con él las extraordinarias gracias de su Sagrado Corazón, las cuales derramaría con abundancia en nuestras conferencias (pp. 160161).

Sobre esta asociación del santo Padre la Colombière a la difusión del culto al Corazón de Jesús, cuenta más adelante Santa Margarita:

Un día que vino a decir Misa en nuestra iglesia, le hizo nuestro Señor, y a mí también, grandísimos favores. Al aproximarme a recibir la Sagrada Comunión, me mostró su Sagrado Corazón como un horno ardiente, y otros dos corazones que iban a unirse y abismarse en él, diciéndome: 'Así es como une para siempre mi puro amor estos tres corazones.' $Y$ después me dio a conocer que esta unión era exclusivamente para la Gloria de su Sagrado Corazón, cuyos tesoros quería descubriese yo al Padre, para que él los diera a 


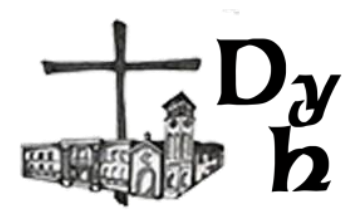

conocer y publicara todo su precio y utilidad (p. 165).

Se nos narra seguidamente cómo tuvo lugar la inicial propagación de estas revelaciones:

como le dijese (al P. la Colombière) que nuestro Señor no me comunicaba estas gracias sino para ser glorificado en las almas, a las cuales había yo de distribuirlas, sea de palabra o por escrito, según Él me diera a conocer su voluntad, sin preocuparme por lo que dijera o escribiera, pues Él derramaría allí la unción de su gracia para producir el efecto, que pretendía en el corazón de cuantos lo recibiesen bien (...) me mandó que, aun a pesar de las grandes penas y humillaciones, que hubiera de sufrir, no desistiese jamás de seguir los santos impulsos de este Espíritu, diciendo simplemente lo que Él me inspirase, y una vez escrito el billete, se lo presentara a la Superiora e hiciese después cuanto ella me ordenara (pp. 166-167).

Así, el sacerdote se transformó en el brazo ejecutivo para concretar esta voluntad del Sagrado Corazón.

Decidido a poner en práctica cuanto el Señor le ordenaba, comenzó por entregarse del todo a la ejecución de la misión recibida (...) Fidelísimo en el dirigir a Santa Margarita María no menos que humilde $y$ abnegado (...) resolvió por lo tanto ser el primero en consagrarse al Corazón divino y escogió para ello precisamente el día indicado por el mismo Salvador. El primer viernes después de la octava del Corpus, 21 de junio de 1675, en que se festeja a San Luis Gonzaga, se consagró al Sagrado Corazón de Jesús con aquel ofrecimiento precioso que él mismo compusiera, al propio tiempo que Santa Margarita María hacía lo mismo en el Monasterio de la Visitación (Colom, 1930, pp. 5556).

Dice el mismo texto sobre el padre la Colombière:

Tenía tan metida en su corazón la propaganda de tan dulce devoción, que en los Ejercicios espirituales de aquel mismo año de 1675 escribía: 'Me impuse la ley de procurar por todas las vías posibles la realización de cuanto me fue impuesto por mi adorable Maestro en lo que toca al culto de su Corazón amantísimo', y en el libro titulado 'Las Contemporáneas', apuntes escritos por las religiosas de Paray-le-Monial, que vivieron en tiempo de Santa Margarita María, se lee: 'nada dejó de hacer el Padre Claudio para que prendiese el fuego de la nueva devoción, introduciendo desde luego la comunión reparadora, los primeros viernes después de la octava del Corpus y los primeros viernes de cada mes.' $Y$ tan patente fue el fruto producido por sus conversaciones, por sus cartas y dirección espiritual en el confesionario, que el mismo Beato Padre no cesaba de admirarse del cambio radical que 
se siguió en muchas almas ( $p$. 59).

Sin embargo, esta hermandad apostólica y espiritual tan profunda se vio muy pronto físicamente disuelta. El P. la Colombière fue en 1676 trasladado a Inglaterra como capellán de la duquesa de York, años antes coronada Reina de Inglaterra, María Beatriz d'Este. Con sus predicaciones, consejos y escritos, el santo sacerdote continuó extendiendo la devoción al Sagrado Corazón y las prácticas de reparación que Este solicitaba. La misma duquesa será quien en 1697, muertos san Claudio y santa Margarita, pedirá (aunque sin éxito inmediato) al Papa Inocencio XII el permiso para celebrar en el día señalado por las revelaciones la fiesta litúrgica del Sagrado Corazón (cf. Viller, 1948, p. 1035).

San Claudio de la Colombière "en Paray, en Londres, en Lyon, se esfuerza discretamente, aunque sin pausa, por responder mediante sus discursos, sus cartas, sus conversaciones, a los pedidos divinos que casi él sólo ha conocido" (Viller, 1948, p. 1034).

Tras la muerte del P. la Colombière, y aun durante los últimos años de vida de la salesa de Paray, son las mismas Visitandinas las que protagonizan el apostolado del Sagrado Corazón junto con algunos sacerdotes de la Compañía, que eran quienes atendían espiritualmente muchos de sus monasterios, como el P. Croiset y el P. Froment.

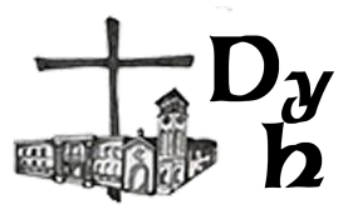

Ciertamente, santa Margarita no llegó a ver en vida el primer florecimiento de la devoción pública al Sagrado Corazón; sin embargo, hacia los últimos años de su vida

tuvo dos consolaciones, las mayores tal vez para un alma, que con tanto ardor deseaba el triunfo de su Amado: ver erigida ya en el recinto de Paray una capilla en honor del Corazón de Jesús, y recibir aquella comunicación íntima, en que le dio a conocer nuestro Señor la misión especial que confiaba a la Compañía de propagar este culto $y$ las gracias singulares que reservaba en la tierra para su elegida milicia (Margarita María de Alacoque, 1890, pp. 230-231).

Sin embargo, será solo con la muerte de la santa, el 17 de octubre de 1690, que se dará abierta publicidad a los manuscritos y revelaciones; y la devoción, desde las Casas Salesianas e Ignacianas, se propagará rápidamente por toda Francia y, luego, por Alemania, Polonia, todo Europa y hasta los continentes de misión. Así lo refiere una biografía de la santa, basada en la primitiva vida que de ella escribió Jean Jaques Languet en 1729:

un escrito del P. de La Colombière pareció digno de darse al público por su piedad (...) esta impresionó a muchos a favor de una devoción cuya práctica estimaba este venerable religioso, haciendo tantos adoradores del sagrado Corazón como lectores tuvo este libro (Languet, 1887, p. 249). 
Ya "el 19 de mayo de 1693, un decreto de Inocencio XII, concede indulgencia plenaria a quienes comulgaren en una iglesia de la Visitación el viernes siguiente a la Octava del Santísimo Sacramento" (Viller, 1948, pp. 1034-1035). Años después, el Santo Padre permitirá celebrar ese día, en las casas visitandinas, la Misa en honor de las Cinco Llagas. Se multiplicaron prontamente las cofradías en honor del Sagrado Corazón: se cuentan dieciocho en 1698, llegan a veintinueve en 1699 y alcanzan el centenar en 1706 (cf. Viller, 1948, p. 1035).

"En 1713 concedió por fin la autoridad eclesiástica licencia para decir la Misa del Sagrado Corazón en la iglesia del convento el viernes después de la Octava del Santísimo Sacramento" (Gauthey, 1921, p. 184). Y luego de 1720, la Celebración Litúrgica se extendió progresivamente a las diócesis de Montauban, Aix, Arles, Autun y Carpentras.

Luego de la publicación de la Vida de Margarita María del P. Languet, el culto del Sagrado Corazón siguió ganando lugar en toda la cristiandad. Grande fue también la actividad del P. Galliffet S.I., que instaba a los reyes de Francia, España y Portugal, que pidiesen a Roma la aprobación universal de la Fiesta. Para 1735 ya existían, en todo el mundo, más de cuatrocientas cofradías en honor del Corazón de Jesús. Por fin, en 1765, bajo el Pontificado de Clemente XIII, la Sagrada Congregación de Ritos aprobó la Misa y el oficio compuestos por los Padres Bruni y Calvi para todo el Reino de Francia (cf. Viller, 1948, pp. 1035-1036 Gauthey, 1921, pp. 186-187).

Como hemos anticipado, la herejía jansenista fue profundamente combativa de la naciente devoción al Sagrado Corazón. En medio de la encarnizada querella de Auxiliis, y sobre todo ante el error de Jansenio que, influenciado por la deficiente teología protestante, negaba en última instancia la universalidad de la Salvación efectuada por Nuestro Señor en la Cruz, las revelaciones del Corazón de Cristo fueron una respuesta, no sistemática y académica, pero sí rotunda $y$ efectiva. Contra el jansenismo, y siguiendo la tradición teológica de la Iglesia, se afirmaba la suficiencia sobreabundante de la Sangre sagrada del Redentor para obrar el rescate de todos los hombres de la esclavitud del pecado (DenzingerHünermann, n²001-2007).

Es por esta razón que el jansenismo persiguió con tanta vehemencia a los promotores del culto al Sagrado Corazón (El Beato Juan Eudes, Vida Popular, pp. 48-50). Llegó aun a condenar como errónea o peligrosa la misma devoción, en el famoso sínodo herético de Pistoya de 1786. Ello dio motivo al Papa Pío VI, en la Contitución Auctorem Fidei de 1794 , en la que se rechazan punto por punto los errores del sínodo jansenista, a efectuar el primer pronunciamiento magisterial a favor delanacientedevoción, argumentando 
que sus promotores "lo adoran en cuanto es Corazón de Jesús, es decir, el corazón de la persona del Verbo, al que está inseparablemente unido, al modo como el cuerpo exangüe de Cristo fue adorable en el sepulcro, durante el triduo de su muerte, sin separación o corte de la divinidad" (Denzinger-Hünermann, $n^{\circ}$ 2663).

Será solo en el siglo XIX que Pío IX extenderá la fiesta a la Iglesia universal. Desde entonces, los Papas sucesivos han ido afianzando y profundizando el culto al Sagrado Corazón como un elemento fundamental y distintivo de la piedad católica ${ }^{2}$.

\section{Consideraciones conclusivas}

Esta forma de Adoración a la segunda Persona de la Trinidad en su humanidad santísima $y$, más concretamente, en el signo sublime de su Corazón de carne, echa sus raíces más profundas en la divina Revelación; como hemos visto, fue haciéndose progresivamente más expresa a través, sobre todo, de la experiencia y los escritos de los santos y místicos de la Iglesia de occidente, hasta quedar constituida en sus rasgos típicos en Francia durante el siglo XVII.

Como mencionamos al hablar del contexto histórico, las revelaciones del Corazón de Jesús a Santa Margarita, y el surgimiento de

${ }^{2}$ Cf. LEÓN XIII, Enc. Annum Sacrum (1899) / Pío XI, Enc. Miserentissimus (1928) / Pío XII, Enc. Haurietis Aquas (1956). esta devoción, en su forma conocida hoy, se dieron en una cristiandad que ya estaba herida en su médula por la división que introdujo la herejía protestante.

En este marco, no resulta casual que las manifestaciones del Corazón divino y la consecuente devoción que promovieron estuvieran, desde su mismo origen, vinculadas a la presencia real de Jesucristo en la Hostia Consagrada. El orden sacramental y, en particular, la Santa Eucaristía, tan cuestionados y aun ultrajados por los dichos $y$ hechos de los protestantes (cf. Denzinger-Hünermann, $\mathrm{n}^{\circ}$ 17511753), fueron objeto del amor y la reparación que esta devoción $y$, por ella, el mismo Cristo, quiso introducir en su Iglesia. Por otro lado, el mismo acto de la reparación, sitúa en su lugar correcto el obrar del creyente que, sostenido por la divina gracia, puede realmente ofrecer a Dios obras buenas y meritorias, que valen no solo para su santificación personal, sino que, unidas al Sacrificio único del Redentor, dan fruto en todo su Cuerpo Místico.

Del mismo modo, la actitud de fe confiada, requerida para la salvación, será también un elemento distintivo de la piedad dirigida al Corazón divino, como vemos sobre todo en los escritos del P. la Colombière (Claudio de la Colomière, pp. 90-92) y en la popular oración Sagrado Corazón de Jesús, en Vos confío; sin embargo, deberá ser purgada o, más bien, exenta del desvío protestante, que no 
comprende la restauración total de la naturaleza que obra la Gracia de Jesucristo a través de los Sacramentos.

También, en plena fidelidad a la tradición católica, sobresale la profunda unión con la que el eudismo veneró a los Corazones de Jesús y María, entendiendo cabalmente el lugar irremplazable que ocupa, en la obra redentora, la Santísima Virgen.

Los siglos que seguirán a nuestro acontecimiento, no serán para Europa ni para la Iglesia menos calamitosos. La propagación de la incredulidad en el siglo XVIII, que dio como fruto nefasto para Francia la Revolución de 1789, con la irrefrenable extensión del liberalismo ateo por todo el mundo occidental, se vio, aunque no frenada, resistida, en más de una ocasión, por los amantes del Corazón de Jesús. Aquellos ideales revolucionarios buscaban, y buscan aún hoy, desterrar a Dios y la religión de la vida pública y de las sociedades, bajo una pretendida irreligión que, en realidad, es inevitablemente una adoración del mismo hombre.

El aspecto de consagración, señalado como distintivo de la devoción al Sagrado Corazón, fue desde el comienzo propuesto no sólo como gesto de religión personal, sino también como declaración de pertenencia y acto de entrega total de la vida del hombre, tanto en su aspecto individual como social, familiar y político; y, en última instancia, como consagración de todo el mundo a quien es su único Rey y Dueño por haberlo creado y redimido, Jesucristo, Señor Nuestro.

Como dirá Pío XII: "Deseamos que cuantos se glorían del nombre de cristianos y combaten por establecer el Reino de Jesucristo en el mundo, consideren la devoción al Corazón de Jesús, como bandera y manantial de unidad, de salvación y de paz" (Pío XII, 1956, n³5).

Podemos reconocer en esta devoción providencial (que Dios mismo ha motivado progresivamente y que ha sido para la Iglesia universal un modo concreto de mantenerse fiel y de profundizar en el divino depósito de la Revelación) un cierto lugar de síntesis para la totalidad del Misterio Cristiano. En él se nos muestra con singular elocuencia el designio salvífico de Dios en los hechos sublimes de la Encarnación del Verbo y de su Pasión, muerte y Resurrección por amor de los hombres. Esta Pasión, representada por la Cruz, la corona de espinas y la herida del costado, es contemplada en su valor sacrificial, expiatorio y salvífico, que se hace presente $y$ operante en el Sacramento Eucarístico y que llama a las almas a unirse a él por la consagración y la reparación.

Por ello, no duda el Papa Pío XII en describirlo como el "acto de religión por excelencia, que consiste en la plena y absoluta voluntad de entregarnos y consagrarnos al amor del Divino Redentor, cuya señal y símbolo más viviente es su Corazón traspasado" (Pío XII, 1956, p. n²). 


\section{Bibliografía}

Claudio de la Colomière, S. (s.f.). Obras Selectas. Editorial Apostolado Mariano.

Colom S.I., P. P. (1930). Breve noticia del Beato Padre Claudio de la Colobiere, S.J. Buenos Aires: Imprenta S. Gir.

del Carmen Blassi, Z. (2001). Cardenal Pedro de Bérulle, su Espiritualidad. La Plata: Ed. F.S.A.

Delgado, G. (2016). Tratado de Gracia. La Plata [apuntes no editados].

Denzinger-Hünermann. (2000). $E l$ Magisterio de la Iglesia. Barcelona: Editorial Herder.

Dodin, A. (1969). La espiritualidad francesa en el siglo XVII. En B. J. Duque, \& L. S. Balust, Historia de la Espiritualidad (Vol. II:Espiritualidad Católica (segunda parte)). Barcelona: Ed. Juan Flors.

El Beato Juan Eudes, Vida Popular. (1922). Besançon: Imprenta Jacques y Demontrond.

Francisco de Sales, S. (1945a). Carta del 10 de junio de 1611. En S. Francisco de Sales, Cartas Espirituales (J. Gutiérrez Gili, Trad.). Barcelona: Ed. Litúrgica Española.

Francisco de Sales, S. (1945b). Carta del 25 de febrero de 1610. En S. Francisco de Sales, Cartas Espirituales (J. Gutiérrez Gili, Trad.). Barcelona: Ed. Litúrgica Española.
Francisco de Sales, S. (2006). Tratado del Amor de Dios. Buenos Aires: Ed. Lumen.

García Herreros, R. (1943). San Juan Eudes. Bogotá: Imprenta Olivieres y Dominguez.

Gauthey, M. (1921). Vida y Obras de Margarita María Alacoque ( $3^{\circ}$ ed., Vols. III, Documentos). (R. d. Madrid, Trad.) Madrid: Edición de las religiosas de la Visitación de Madrid.

Huerga, A. (1969). La vida crisitana en los siglos XV-XVI. En B. J. Duque, $\&$ L. S. Balust, Historia de la Espiritualidad. Barcelona: Ed. Juan Flors.

Languet, J. J. (1887). Vida de la Beata Margarita María de Alacoque. Barcelona: Imprenta de Francisco Rosal.

Llorca, Villoslada, \& Montalbán. (1958). Historia de la Iglesia Católica (Vol. III: Edad Nueva). Madrid: Ed. B.A.C.

Llorca, Villoslada, \& Montalbán. (1960). Historia de la Iglesia Católica (Vol. IV: Edad Moderna). Madrid: Ed. B.A.C.

Margarita María de Alacoque, S. (1890). Autobiografía. (P. Á. S.I., Trad.) Bilbao.

Pío XII, P. (1956). Haurietis Aquas. Vaticano: Editrice Vaticana.

Pontificio Ateneo Lateranense (1950). Enciclopedia Cattolica (Vol. IV). Vaticano: Casa Editrice G. C. Sansoni. 


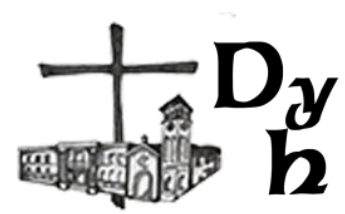

Viller S.I., M. P. (1948). Diccionaire de Spiritualité. París: Ed. Beauchesne et ses Fils. 